\title{
Double-stranded RNA antibodies in systemic lupus erythematosus
}

\author{
PAUl DAVIS, PETER CUNNINGTON, AND GRAHAM R. V. HUGHES \\ From the Department of Medicine, Bristol Royal Infirmary, Beecham Research Laboratories, Betchworth; and \\ Department of Medicine, Royal Postgraduate Medical School, London
}

\begin{abstract}
Davis, P., Cunnington, P., and Hughes, G. R. V.(1975). Annals of the Rheumatic Diseases, 34, 239-243. Double-stranded RNA antibodies in systemic lupus erythematosus. Antibodies to viral double-stranded RNA (ds RNA) have been found in $40 \%$ of patients with systemic lupus erythematosus (SLE) and $14.5 \%$ of patients with rheumatoid arthritis. These antibodies were diagnostically more specific for SLE than those directed against artificial polynucleotides, poly I:C and poly A:U. Although not disease specific, high titres of antibody to ds viral RNA were found almost exclusively in SLE. Serial studies failed to show that RNA antibody levels correlated with disease activity.

Although of considerable interest in experimental studies on the pathogenesis of SLE, ds viral RNA antibodies are of little clinical significance in the management of SLE.
\end{abstract}

Systemic lupus erythematosus (SLE) is characterized by a wide variety of circulating antibodies. In particular, antibodies against double-stranded DNA (ds DNA) have been shown to have clinical significance in their diagnostic specificity and sensitivity in SLE (Hughes, 1971; Hughes, Cohen, and Christian, 1971). Of interest has been the demonstration in SLE of antibodies directed against double-stranded RNA (ds RNA) (Schur and Monroe, 1969; Talal, 1973). This finding, together with the fact that most human RNA is single stranded, has led to the suggestion that these antibodies may be directed against viral antigens (Schur, Stollar, Steinberg, and Talal, 1971).

$A$ variety of methods has been used in the detection of RNA antibodies, including the sensitive Farr technique (Wold, Young, Tan, and Farr, 1968) and the filter radioimmunoassay technique (Attias, Sylvester, and Talal, 1973). The antigen most widely used in these techniques has been the synthetic polynucleotide poly inosinic:poly cytidylic acid (poly $\mathrm{I}: \mathrm{C}$ ), which has structural and chemical similarities to ds RNA. Using this technique, Schur and his colleagues (1971) detected antibodies against poly $\mathrm{I}: \mathrm{C}$ in $51 \%$ of SLE sera, but these were not specific, also being found in $9 \%$ of patients with rheumatoid arthritis (RA) and in $6 \%$ of normals. In the present study we have substituted the synthetic polynucleotide poly I:C for a highly purified preparation of doublestranded viral RNA obtained from Penicillium cultures, and assessed the frequency and specificity of Accepted for publication October 24, 1974.

Correspondence to Dr. P. Davis, Dept. of Medicine, Bristol Royal Infirmary. these antibodies for SLE. Comparisons were made with the titres and frequencies of antibodies against other synthetic polynucleotides.

\section{Materials and methods}

Serum was obtained from 39 normal volunteers, 89 patients with SLE, 37 with RA, and 20 with discoid lupus erythematosus. Sera were stored in aliquots at $-20^{\circ}$ and each used once only.

${ }^{14}$ C-labelled DNA was obtained (Radiochemical Centre, Amersham) and DNA antibody measurements carried out as previously described (Pincus, Schur, Rose, Decker, and Talal, 1969; Hughes, and others, 1971). Measles antibody estimations were performed (by Dr. G. Agnirsdottir) using the haemagglutination-inhibition technique. Antibodies to viral RNA were measured using BRL 5907, an extract produced and purified from a Penicillium culture infected with ds RNA virus, by the method of Banks, Buck, Chain, Darbyshire, and Himmelweit (1969), and labelled with tritium. The ds RNA when purified was essentially free from protein and had a sedimentation coefficient of $12 \mathrm{~S}$. It has a well-defined molecular weight composition of $2 \times 10^{6}$ and gave a single OD peak at $280 \mathrm{~nm}$ on Sepharose 2B chromatography. The ds RNA exhibited marked hyperchromicity and melting profile when heated and was much more resistant to bovine pancreatic ribonuclease than was single-stranded RNA (Cunnington and Naysmith, 1975). Synthetic polynucleotides, poly I: Cand poly A: U (supplied by Beecham Labs.), and ds RNA antibodies were measured by the following technique.

RNA-BINDING TECHNIQUE

$0.05 \mathrm{ml}$ of test sera diluted 1:10 with borate buffer $(\mathrm{pH}$ 
8.0) was incubated with an equal volume of labelled test antigen. Optimum antigen concentrations determined by plotting antigen/antibody curves were $0.01 \mu \mathrm{g}$ per test for viral RNA, poly I:C, and poly A:U. Maximum precipitation of antigen/antibody complexes was achieved with an equal volume of saturated ammonium sulphate to a final concentration of $50 \%$.

Inhibition studies were performed after preincubation at $37^{\circ} \mathrm{C}$ for $1 \mathrm{~h}$ with a twentyfold excess of nonradioactive ds and ss DNA, ds and ss RNA, and poly I:C and poly A:U.

\section{Results}

The incidence of antibodies to the various nuclear and viral antigens tested are summarized in Table I. Using ds viral RNA, antibodies were found in 45 of 112 SLE sera tested (40\%). A significant but lower inci- dence of these antibodies was also found in 5 of 37 RA sera (14.5\%), 2 of 10 discoid LE sera (10\%), and 1 of 39 normal controls $(2.5 \%)$. Levels of RNA antibodies in all groups are shown in Fig. 1.

COMPARISON OF DS RNA AND SYNTHETIC

POLYNUCLEOTIDES

Twenty-nine SLE sera in which ds RNA antibodies had been detected were also tested for the presence of antibodies to the synthetic polynucleotides, poly I:C and poly $\mathrm{A}: \mathrm{U}$. Antibodies to poly $\mathrm{I}: \mathrm{C}$ were found in $66 \%$ and to poly A:U in $13 \%$ of these cases. Fig. 2 shows the relationship of viral RNA to poly $\mathrm{I}: \mathrm{C}$ binding in SLE patients. A small number of sera appeared to react almost exclusively with viral RNA. Antibodies to poly I: $\mathrm{C}$ were detected in 17 of $32 \mathrm{RA}$ sera tested $(53 \%)$. Only four of these patients had antibodies against ds RNA.

Table I Incidence of antibodies to viral ds $R N A, d s D N A$, and synthetic polynucleotides

\begin{tabular}{|c|c|c|c|c|c|}
\hline & ds viral $R N A$ & Poly I: C & Poly A: $U$ & $d s D N A$ & $\begin{array}{l}\text { Measles } \\
\text { antibody } \\
(>1: 32)\end{array}$ \\
\hline $\begin{array}{l}\text { SLE } \\
\text { RA } \\
\text { DLE } \\
\text { Normal controls }\end{array}$ & $\begin{array}{c}45: 112(40 \%) \\
5: 37(14 \cdot 5 \%) \\
2: 10(10 \%) \\
1: 39(2.5 \%)\end{array}$ & $\begin{array}{l}18: 27(66 \%) \\
17: 32(53 \%) \\
0: 17\end{array}$ & $\begin{array}{l}2: 15(13 \%) \\
\overline{\overline{0}}\end{array}$ & $\begin{array}{c}94: 112(85 \%) \\
0: 37 \\
7: 27(27 \%) \\
0: 39\end{array}$ & $13: 21(64 \%)$ \\
\hline Normal level & $7 \%$ & $15 \%$ & $4 \%$ & $30 \%$ & $1: 32$ \\
\hline
\end{tabular}

ANT IBODIES TO DOUBLF-STRANDED R N A

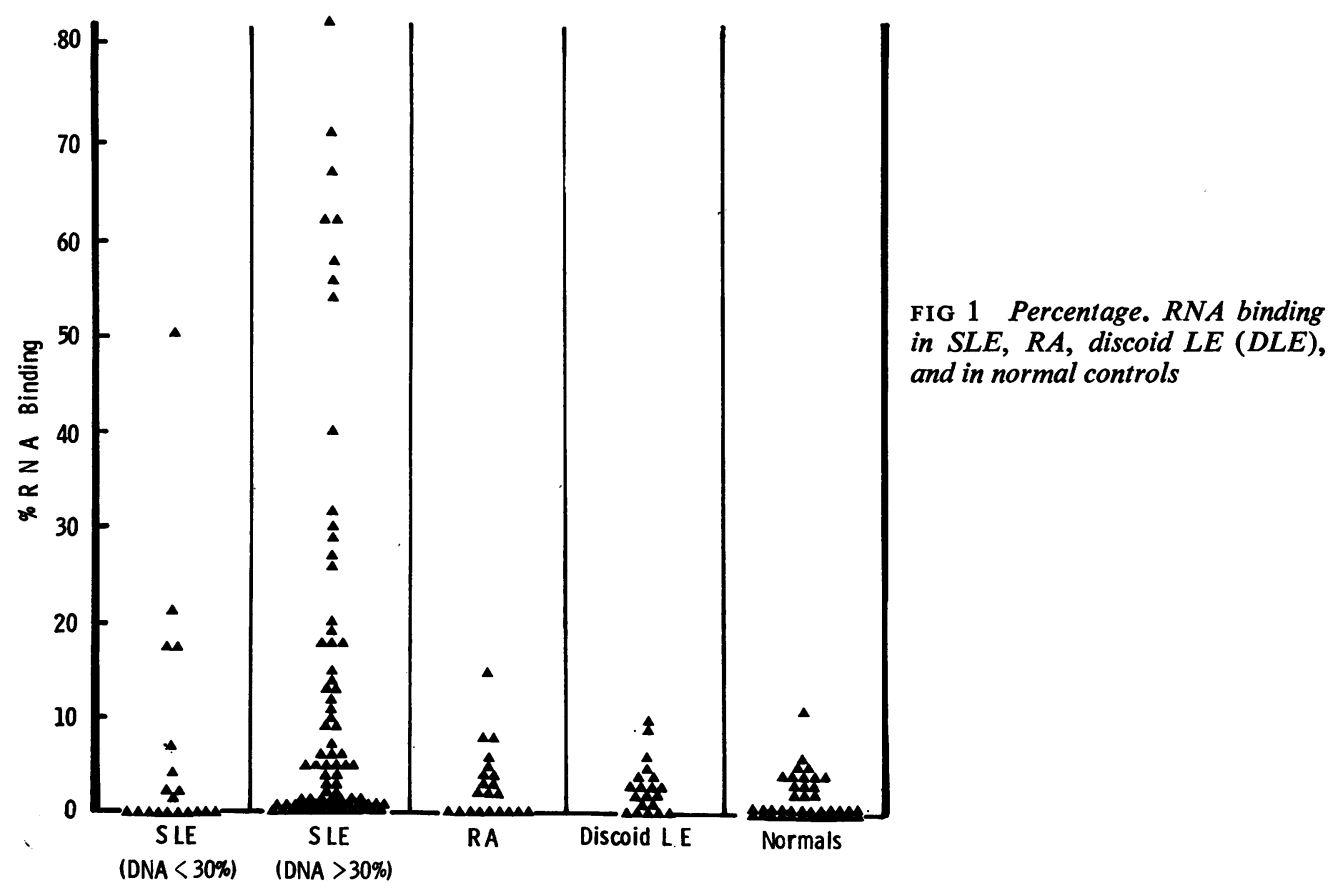

FIG 1 Percentage. $R N A$ binding (DLE), and in normal controls 


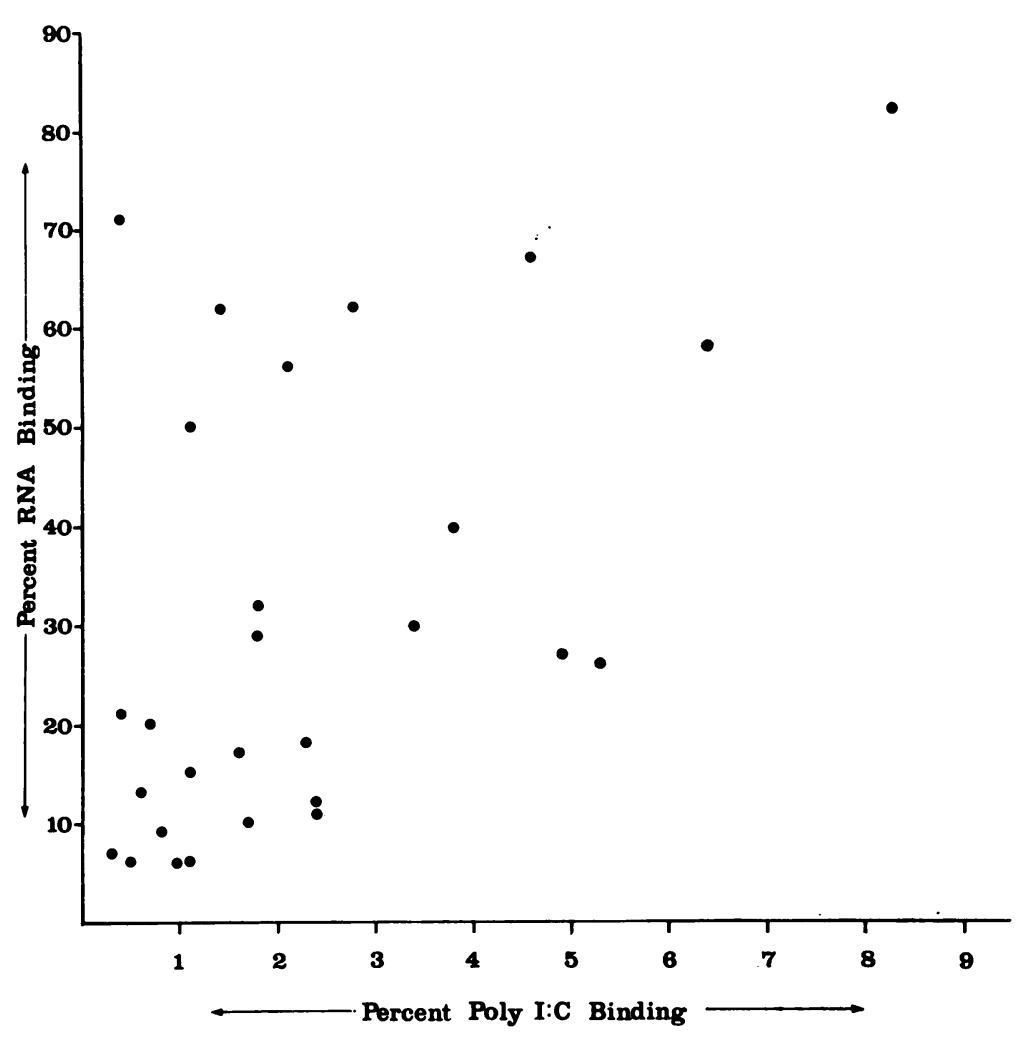

FIG. 2 RNA versus poly I:C binding in SLE patients

\section{COMPARISON OF DS RNA AND DS DNA} ANTIBODIES

Of the 112 serum specimens tested from 89 patients with SLE, $94(85 \%)$ contained antibodies to ds DNA. Of the group of patients with raised DNA binding, all of whom had active SLE, 39 (42\%) also had antibodies to ds viral RNA. Of the 18 sera without DNA antibodies, $6(33 \%)$ had antibodies to the ds viral RNA. There were no clinical features within these two groups to suggest why RNA antibodies were found in some patients and not in others. While there was a correlation between the titre of antibody to DNA and to RNA, again wide individual variation was seen.
Of the 27 patients with discoid LE tested, seven (27\%) had antibodies to ds DNA as previously reported (Davis and Hughes, 1974). Two of twenty tested for ds RNA antibodies had slightly raised titres.

\section{SERIAL STUDIES}

Serial studies ( 3 or more sequential measurements) were performed in six patients with SLE. In only one patient was there a direct correlation between a rising or falling titre of RNA antibodies and clinical activity. In two patients a consistently high RNA antibody titre was noted despite fluctuating disease activity and DNA binding activity. 


\section{MEASLES}

Measles antibody titres were measured in 21 patients with SLE. In our group titres were raised in $64 \%$ of cases and showed an overall, though indirect, correlation with raised levels of both ds DNA and ds RNA antibodies. In 9 sera from patients convalescing from measles infection and 5 with influenza, anti ds RNA and DNA antibodies were not detectable.

\section{INHIBITION STUDIES}

Inhibition studies were carried out on sera from six patients with high levels of viral RNA antibodies (Table II). A mean inhibition of $97 \%$ was obtained with nonradioactive viral RNA and $69 \%$ with poly I:C. Incubation with ss RNA and ss DNA resulted in relatively poor inhibition, as did incubation with artificial polynucleotide poly $\mathrm{A}: \mathrm{U}$. Variable inhibition was obtained by incubation with ds DNA. The mean inhibition was $56 \%$. Three patients showed inhibition of $80 \%, 94 \%$, and $69 \%$, respectively, while in the remaining three, inhibition was relatively poor. Again there were no distinguishing features between these two groups.

\section{Discussion}

Most recent attempts to detect and characterize antiRNA antibodies have used the synthetic polynucleotides poly $\mathrm{I}: \mathrm{C}$ and poly $\mathrm{A}: \mathrm{U}$. Schur and Monroe (1969), using an Ouchterlony immunodiffusion method, detected antibodies against poly $\mathrm{I}: \mathrm{C}$ in sixteen out of 89 SLE patients (18\%). Koffler, Agnello, Thorburn, and Kunkel (1971), with a haemagglutination method again using poly $\mathrm{I}: \mathrm{C}$ as the antigen, detected antibodies in 13 out of 60 SLE sera. Schur and others (1971) compared Ouchterlony immunodiffusion, microcomplement fixation, and the Farr ammonium sulphate precipitation method, using a variety of synthetic polynucleotides. Precipitating antibodies were found against poly $\mathrm{I}: \mathrm{C}$ in $17 \%$ of SLE sera and $4 \%$ of RA sera. Using the more sensitive Farr method, $51 \%$ of SLE and $9 \%$ of RA sera showed raised binding activity against poly I:C. Attias and others (1973), using the more sensitive filter radioimmunoassay, found antibodies to rheovirus RNA in $70 \%$ of SLE sera but in only $14 \%$ of RA sera and $4 \%$ of controls.

Our present studies, using viral RNA confirm the high incidence of antibodies to ds RNA in SLE. While it is shown that variable cross-reactivity of these antibodies with other polynucleotides may occur, it is possible that, as in the case of anti-DNA antibodies, a variety of anti-ds RNA antibodies with differing specificities may be found.

The origin of the antigen is at present unknown. Human RNA is predominantly single stranded, though transfer RNA has helical regions in its structure. However, Talal, Steinberg, and Daley (1971) failed to achieve significant inhibition of poly 3 I:C binding by human SLE serum with transfer RNA. These and other observations have led to suggestions that the antigen may be viral in nature (Talal, $\overrightarrow{\bar{N}}$ 1970). Raised antibody titres to a number of viruses, $\overrightarrow{0}$ particularly myxoviruses, have been observed in $\frac{\overline{0}}{0}$ SLE (Phillips and Christian, 1970), though these in- $\overline{\bar{c}}$ creases may reflect the overall production of humoral $\mathbb{\Phi}$ antibodies characteristic of SLE. In our own series the mean $\mathrm{H}$ :I titre of measles antibodies was raised ${ }^{\infty}$ in the SLE group, confirming the original observa- $\vec{O}$ tions of Phillips and Christian, but there was no direct $\overrightarrow{\vec{H}}$ relationship between anti-ds RNA antibody and measles antibody titres. We were, equally, unable to detect anti-ds RNA antibodies in convalescent sera from other myxovirus infections. Schur and others $\underset{\oplus}{\omega}$ (1971) found no increase in antibodies to ds RNA $\omega$ (poly I:C) after acute infection with influenza virus, despite fourfold rises in antibody titres to influenza A2 antigens.

Support for the antigenic RNA being viral in origin $\vec{c}$ came from the observations of Talal and others (1971) who, using inhibition of binding of poly I:C by various RNAs, observed that sera from New $\vec{\varphi}$ Zealand mice immunized with synthetic RNA reacted or poorly with viral RNA, whereas mice immunizel with viral RNA reacted with both synthetic and vira RNA, as in the case of human lupus sera. A third po sible source of antigen might be ds RNA induced in mammalian cells as a consequence of viral infection (Stollar and Stollar, 1970).

Talal and Gallo (1972) have demonstrated antibodies to synthetic RNA-DNA hybrids in a small number of SLE sera. Such hybrid molecules are formed during the replication cycle of RNA tumour viruses, which contain the enzyme reverse transcrip- $\frac{0}{2}$ tase. Thus, the finding of these antibodies has been $\overline{0}$ taken as further support for the presence of an RNA virus in the tissues of SLE patients.

If the source of the antigen is not known, the pathogenetic role of RNA and RNA antibodies in human 0 SLE is equally uncertain at the present time. The elution studies of Koffler and others (1971) failed to show anti-ds RNA antibodies in SLE glomeruli, though this of itself does not rule out a pathogenetic $N$ role for RNA/anti-RNA complexes. The synthetic $N$ polynucleotides are known adjuvants and in the ్ㅗ NZB/W hybrid mouse immunization with synthetic 0 polynucleotides greatly accelerates immune complex nephritis largely through the accelerated formation of antibodies to RNA and DNA in these animals (Talal, $\stackrel{\oplus}{\rightarrow}$ 1970). It is possible that the genetic factors predisposing to the heightened production of antibodies to RNA in these animals may also be present in SLE.

From the clinical viewpoint, it is clear that in many $\overrightarrow{\mathbb{D}}$ human SLE sera, and in some patients with discoid $\frac{\varrho}{\sigma}$ LE, antibodies are present which are directed against 
viral double-stranded RNA and which are distinct from those directed against DNA and other polynucleotides. Their contribution, if any, to immune complex formation is as yet unknown.

\section{References}

Attias, M. R., Sylvester, R. A.. And Talal, N. (1973) Arthr. and Rheum., 16, 719 (Filter radioimmunoassay for antibodies to rheovirus RNA in systemic lupus erythematosus).

Banks, G. T., Buck, K. W., Chain, E. B., Darbyshire, J. E., AND Himmelweit, F. (1969) Nature (Lond.), 222, 89 (Virus-like particles in penicillin producing strains of Penicillium chrysogenum)

Cunnington, P. G., AND NAYSMITH, J. D. (1975) Immunology, 28, 451 (Naturally occurring double-stranded RNA and immune responses)

Davis, P., AND Hughes, G. R. V. (1974) Brit.J. Derm. 91, 175 (DNA antibodies in discoid LE)

HUGHES, G. R. V. (1971) Lancet, 2, 861 (Significance of anti-DNA antibodies in systemic lupus erythematosus) , Cohen, S. A., ANd Christian, C. L. (1971) Ann. rheum. Dis., 30, 259 (Anti DNA activity in systemic lupus erythematosus)

Koffler, D., Agnello, V., Thorburn, R., AND Kunkel, H. G. (1971) J. exp. Med., 134, 169S (Systemic lupus erythematosus. Prototype of immune complex nephritis in man)

Phillips, P. E., AND Christian, C. L. (1970) Science, 168, 982 (Myxovirus antibody increases in human connective tissue disease)

Pincus, T., Schur, P. H., Rose, J. A., Decker, J. L., And Talal, N. (1969) New Engl. J. Med., 281, 701 (Measurement of serum DNA-binding activity in systemic lupus erythematosus)

SChUR, P. H., AND Monroe, M. (1969) Proc. Nat. Acad. Sci. (U.S.A.), 63, 1108 (Antibodies to ribonucleic acid in systemic lupus erythematosus)

-, Stollar, B. D., Steinberg, A. D., and Talal, N. (1971) Arthr. and Rheum., 14, 342 (Incidence of antibodies to double-stranded RNA in systemic lupus erythematosus and related diseases)

Stollar, V., and Stollar, B. D. (1970) Proc. Nat. Acad. Sci. (U.S.A.), 65, 993 (Immunochemical measurement of double-stranded RNA of uninfected and arbovirus-infected mammalian cells)

TALAL, N. (1970) Arthr. and Rheum., 13, 887 (Immunologic and viral factors in the pathogenesis of systemic lupus erythematosus)

- (1973) Clin. immunol. pathol., 1, 230 (Antibodies binding H-rheovirus RNA in systemic lupus erythematosus)

-, AND GALLO, R. C. (1972) Nature (New Biol.), 240, 240 (Antibodies to a DNA: RNA hybrid in systemic lupus erythematosus measured by a cellulose ester filter radioimmunoassay)

—, Steinberg, A. D., AND Daley, G. G. (1971) J. clin. Invest., 50, 1248 (Inhibition of antibodies binding polyinosinic polycytidylic acid in human and mouse lupus sera by viral and synthetic ribonucleic acids)

Wold, E. T., Young, F. E., TAN, E. M., AND FARR, R. S. (1968) Science, 161, 806 (Deoxyribonucleic acid antibody: a method to detect its primary interaction with deoxyribonucleic acid) 